\title{
Dimerization of Pyramidalized 3,4,8,9-Tetramethyltetracyclo [4.4.0.03,9.04,8]dec-1(6)-ene to a Hydrocarbon Featuring Four Cyclohexane Rings in Boat Conformations**
}

\author{
Matias Rey-Carrizo, Marta Barniol-Xicota, Mercè Font-Bardia, and Santiago Vázquez*
}

[*] M. Rey-Carrizo, M. Barniol-Xicota, Prof. Dr. S. Vázquez Laboratori de Química Farmacéutica (Unitat Associada al CSIC), Facultat de Farmàcia, and Institute of Biomedicine (IBUB), Universitat de Barcelona Av. Joan XXIII, s/n, 08028 Barcelona (Spain)

E-mail: svazquez@ub.edu

Homepage:

http://www.ub.edu/farmaco/ca/farmaceutica/recerca/novel_polycyclic_compounds_with_biological_acti $\underline{\text { vity/8/ }}$

Dr. M. Font-Bardia Unitat de Difracció de RX, Centres Científics i Tecnològics (CCiTUB), Universitat de Barcelona Solé i Sabarís 1-3, 08028 Barcelona (Spain)

[**] S.V. thanks Ministerio de Ciencia e Innovación (project CTQ2011-22433) and the Generalitat de Catalunya (grant SCG-2009-294) for financial support. M.R.-C. thanks the Govern d'Andorra for a PhD grant (ATCR2012/2013-00XX-AND). We thank Prof. F. J. Luque for helping us with the theoretical calculations. 


\section{ABSTRACT}

43 The synthesis, chemical trapping, and dimerization of a highly pyramidalized alkene is reported. Its 44 dimer is a unique nonacycle featuring three planar cyclobutane rings, four cyclopentane rings, and four 45 cyclohexane rings in boat conformations. The $\mathrm{X}$-ray diffraction analysis showed a $\mathrm{H}-\mathrm{H}$ distance 46 between the flagpole hydrogen atoms of $1.999 \AA$ and a separation of $2.619 \AA$ between the two flagpole 47 carbon atoms. The three cyclobutane rings of the dimer were thermally stable 
Pyramidalized alkenes are compounds containing carbon-carbon double bonds in which one or both of generation, trapping, and dimerization of several highly pyramidalized alkenes and the first crosscoupling of two different pyramidalized alkenes leading to a tetrasecododecahedradiene derivative.[1c, 2, 3] Herein, we report the generation of 4 (Scheme 1), a novel highly pyramidalized alkene, its trapping with 1,3-diphenylisobenzofuran, and its dimerization to a unique polycyclic hydrocarbon, 7, which features three planar cyclobutane rings, four cyclopentane rings, and four cyclohexane rings in a boat conformations.

Theoretical calculations using B3LYP/6-31G(d) showed us that the alkene 4 should be an accessible target.[4] Its calculated pyramidalization angle $(\mathrm{F}=47.58)$, [5] carbon-carbon double bond length $(1.360$ $\AA)$, heat of hydrogenation (-63.7 kcalmol-1), HOMO-LUMO gap $(5.64 \mathrm{eV})$, and predicted 13C NMR chemical shift $(\mathrm{d}=148.4 \mathrm{ppm})$ were in line with the values calculated for previously synthesized highly pyramidalized alkenes.[1c, 6]

It is known that vicinal diiodo compounds are suitable precursors of highly pyramidalized alkenes, so the generation of 4 was envisioned from the diiodo derivative 3 (Scheme 1), whose preparation from the known anhydride 1[7] was carried out in just two steps. Saponification of 1 gave the dicarboxylic acid 2 in $70 \%$ yield. The diiodo compound 3 was obtained in $27 \%$ yield by using a iododecarboxylation procedure recently reported by Gandelman and co-workers.[8] Previous attempts to carry out the iododecarboxylation of 2 using iodosobenzene diacetate or lead tetraacetate gave even lower yields of 3. Reaction of 3 with tert-butyllithium in THFat $-67^{\circ} \mathrm{C}$ in the presence of 1,3-diphenylisobenzofuran furnished the expected Diels-Alder adduct 5 in 37\%yield. Finally, reaction of 3 with a large excess of molten sodium in 1,4-dioxane at reflux for 4 hours gave a mixture of three products (GC/MS): the reduced product 6 , the expected dimer 7 , and the dihydrodimer 8 . From this mixture, 6 was isolated by sublimation (100 8C at 1 Torr), 7 was obtained by crystallization from n-pentane, and 8 was obtained from the mother liquors. X-Ray diffraction analysis unequivocally established the structures of 7 and 8.[9]

The X-ray diffraction analysis of 7 revealed several interesting features. Firstly, 7 has three planar cyclobutanes, two of them with four eclipsed methyl groups. While the central cyclobutane is not a fully perfect square, as it has two newly formed carbon-carbon bonds being slightly shorter than the other two bonds, the other two cyclobutanes are nearly perfect squares (see Figure 1). Secondly, the compound has four cyclopentane rings in a "frozen" envelope conformation. Finally, the structure features four cyclohexane rings in a boat conformation. Although there are several precedents of cyclohexane rings in boat conformations, [10] most of the known examples lack the typical $\mathrm{H}-\mathrm{H}$ flagpole interaction of the boat conformation (e.g. camphor and other norbornane derivatives).[11] Some notable exceptions with frozen boat cyclohexanes, featuring a $\mathrm{H}-\mathrm{H}$ flagpole interaction, are the asteranes, such as tetracyclo [3.3.1.02,8.04,6]nonane (triasterane; 9)[12] tricyclo[3.1.1.12,4]octane (diasterane; 10),[12d, 13] and pentacyclo[6.4.0.02,7.04,11.05,10] dodecane (tetraasterane; 11),[12a,d, $14,15]$ and tetracyclo[5.3.1.12,6.04,9]dodecane (iceane; 12$),[16]$ a polycyclic compound featuring two chair and three boat cyclohexane rings (Figure 2). Interestingly, the cyclobutane rings of these polycyclic compounds can be either planar, as in 7 and 11, or puckered as in 10 .

According to a seminal paper by Hassel and Ottar,[17] the boat conformer of the cyclohexane ring with fixed C-C-C angles of $109.5^{\circ}$ would have a distance between the flagpole hydrogen atoms of $1.8-1.83 \AA$ and a separation of $2.57 \AA$ would be expected between the flagpole carbon atoms. These distances should induce severe steric congestion given the van der Waals radius of hydrogen and carbon, 1.1-1.2 $\AA$ and 1.7-1.8 $\AA$, respectively.[18] In fact, Sauers has found, using density functional calculations at the B3LYP/6-311++G(2d,p) level of theory, that the boat conformer of cyclohexane suffers from significant distortions from pure sp3 hybridization, thus relieving the flagpole $\mathrm{H}-\mathrm{H}$ interaction at an interatomic 
separation of $2.353 \AA$ and with a distance of $2.736 \AA$ between the two flagpole carbon atoms.[11a] In this work, for the boat conformer of cyclohexane, we have found smaller distances using MP2/6$31 \mathrm{G}(\mathrm{d}): 2.289 \AA$ and $2.710 \AA$ for the flagpole $\mathrm{H}-\mathrm{H}$ and $\mathrm{C}-\mathrm{C}$ interatomic distances, respectively.[4]

However, in the polycyclic compounds shown in Scheme 1 the ability of the boat cyclohexanes to relieve the flagpole $\mathrm{H}-\mathrm{H}$ interaction is severely limited. Thus, the X-ray diffraction analysis of 7 revealed a distance between the flagpole hydrogen atoms of only $1.999 \AA$ and a separation of $2.619 \AA$ between the flagpole carbon atoms. We have optimized the structure of 7 at the MP2/6-31G(d) level of theory and found distances of $2.042 \AA$ and $2.668 \AA$ for the flagpole $\mathrm{H}-\mathrm{H}$ and $\mathrm{C}-\mathrm{C}$ distances, respectively, and they are in reasonable agreement with the experimental values. At this level, these distances are shorter than the corresponding values found in 9,11 , and 12, but longer that those of 10 (Table 1).[4]

Regarding the X-ray diffraction analysis of 8 two features are worthy of comment. Firstly, values between 1.93 and $2.03 \AA$ were found for the distance between the flagpole hydrogen atoms, while an average value of $2.64 \AA$ was found between the flagpole carbon atoms, very similar to the values found for 7. These values are also very similar in the X-ray diffraction structures found for 1, 3, and 5.[9] Secondly, the exocyclic intercage C-C bond length of 8 is $1.539(3) \AA$, the normal length for a C-C single bond, midway between the very short intercage $\mathrm{C}-\mathrm{C}$ bond found in tetrahedranyltetrahedrane and bicubyl derivatives, which feature significantly shorter distances (around 1.44-1.46 $),[19]$ and that of the 1-(1-adamantyl)adamantine (1.578(2) $\AA$ ).[20]

Previously, we had observed that several cyclobutane dimers of highly pyramidalized alkenes underwent an exothermic [2+2] retrocycloaddition process to their corresponding diene isomers.[1, 3d] However, the three cyclobutane rings in 7 were thermally stable. In fact, the only process that was observed when a sample of 7 was heated up to $5008 \mathrm{C}$ was the melting process at $3808 \mathrm{C}$. MP2/6-311++G(d,p)//MP2/6$31 \mathrm{G}(\mathrm{d})$ calculations carried out on 7 and its three theoretical diene isomers, 13, 14, and 15, predicted endothermic processes for all the ring-opening reactions, with the transformation of 7 into 13 being more endothermic, $17.8 \mathrm{kcalmol}-1$, than the opening to 14 or $15,11.5$ and 11.4 kcalmol-1, respectively, thus probably reflecting the increase in the strain in 13 as a consequence of the approaching of the eclipsed methyl groups (Scheme 2).[4]

In summary, we have presented here the synthesis, chemical trapping, and dimerization of a highly pyramidalized alkene. Its dimer features three planar cyclobutane rings and four cyclohexane rings in boat conformations. X-ray structural studies and theoretical calculations showed that the distances between the flagpole hydrogen atoms and the flagpole carbon atoms are smaller than the sum of the van der Waals radius of the involved atoms. Finally, in spite of the three cyclobutane rings, and in sharp contrast with the behavior of previously described dimers of highly pyramidalized alkenes, the nonacycle 7 is thermally stable. 
141 Keywords: ab initio calculations $\cdot$ dimerization $\cdot$ hydrocarbons $\cdot$ polycycles $\cdot$ strained molecules 142 


\section{EXPERIMENTAL SECTION}

3,4,8,9-Tetramethyltetracyclo[4.4.0.03,9.04,8]decane-1,6-dicarboxylic acid (2): A solution of the anhydride $1(270 \mathrm{mg}, 1.03 \mathrm{mmol})$ in $1 \mathrm{n} \mathrm{NaOH}(10 \mathrm{~mL})$ was heated to reflux for $18 \mathrm{~h}$. The suspension was allowed to cool down to room temperature, was acidified with $6 \mathrm{n} \mathrm{HCl}$, and extracted with EtOAc (3 [ $50 \mathrm{~mL}$ ). The organic phase was dried over anhydrous $\mathrm{Na} 2 \mathrm{SO} 4$ and concentrated under reduced pressure to give 2 (203 mg, 70\% yield) as a colorless solid, m.p. 209-2108C. 1H NMR (400 MHz, [D6]DMSO): d=0.92 (s, 12H, 3(4,8,9)-CH3], 0.98 [d, J=11.6 Hz, 4H, 2(5,7,10)-Ha], 1.97 ppm [d, $\mathrm{J}=11.6 \mathrm{~Hz}, 4 \mathrm{H}, 2(5,7,10)-\mathrm{Hb}]$; 13C NMR (100.6 MHz, CD3OD): $\mathrm{d}=15.7$ [CH3, 3(4,8,9)-CH3], 43.5 [CH2, 2(5,7,10)-CH2], 46.4 [C, 3(4,8,9)-C], 53.7 [C, 1(6)-C], 179.1 ppm (C, CO2H); IR (KBr): $\mathrm{n}=3000-2400(2953,2921,2867,2673,2570), 1717,1429,1299,1218,1176,1116,1061,1030,1013$, 877, 771, $720 \mathrm{~cm} \quad$ 1; GC/MS (70 eV): m/z (\%): 260 [(M H2O)C+, 5], 232 (51), 187 (100), 173 (73), 163 (19), 159 (15), 145 (34), 131 (23), 119 (37), 105 (17), 91 (36), 82 (37), 77 (31), 67 (17); Accurate mass [ESI $(\quad)$ ]: $\mathrm{m} / \mathrm{z}$ calcd for $\mathrm{C} 16 \mathrm{H} 21 \mathrm{O} 4: 277.1445[\mathrm{M} \mathrm{H}]$; found: 277.1448 .

1,6-Diiodo-3,4,8,9-tetramethyltetracyclo[4.4.0.03,9.04,8]decane (3): 1,3-Diiodo-5,5-dimethylhydantoin $(7.17 \mathrm{~g}, 18.9 \mathrm{mmol})$ was added to a solution of the diacid $2(2.10 \mathrm{~g}, 7.54 \mathrm{mmol})$. The resulting orange solution was irradiated ( $2 \square 60 \mathrm{~W}$ tungsten bulb) at reflux for $24 \mathrm{~h}$. The suspension was cooled to room temperature and washed with $10 \%$ aqueous NaHSO3 $(50 \mathrm{~mL})$. The aqueous layer was extracted with $\mathrm{CH} 2 \mathrm{Cl} 2(25 \mathrm{~mL})$ and the combined organic layers were washed with saturated aqueous solution of $\mathrm{NaHCO} 3(2 \mathrm{2} 25 \mathrm{~mL}$ ), dried over Na2SO4, filtered, and concentrated under vacuum to obtain $1.4 \mathrm{~g}$ of a mixture of starting 2, 3 and the corresponding iodoacid. Purification by column chromatography (silica gel, n-hexane) gave 3 as a colorless solid (900 mg, 27\% yield), m.p. 234-2358C. 1H NMR (400 MHz, $\mathrm{CDCl} 3$ ): $\mathrm{d}=0.92$ (s, 12H, 3(4,8,9)-CH3], 1.62 [d, J=12.0 Hz, 4H, 2(5,7,10)-Ha], 2.69 ppm [d, J=12.0 Hz, 4H, 2(5,7,10)-Hb]; 13C NMR (100.6 MHz, CDCl3): d=14.3 [CH3, 3(4,8,9)-CH3], 47.0 [C, 3(4,8,9)- C], 48.7 [C, 1(6)-C], 53.7 ppm [CH2, 2(5,7,10)-CH2]; IR (KBr): n= 2923, 2859, 1717, 1448, 1384, 1369, 1298, 1270, 1208, 1187, 1102, 935, 820, 790, 708, $654 \mathrm{~cm} \mathrm{1;} \mathrm{GC/MS} \mathrm{(70} \mathrm{eV):} \mathrm{m/z} \mathrm{( \% ):} 442(\mathrm{MC}+, 2)$, 315 (46), 187 (100), 173 (46), 159 (13), 145 (34), 131 (16), 119 (23), 105 (11), 91 (20), 77 (12); Anal calcd for $\mathrm{C} 14 \mathrm{H} 20 \mathrm{I} 2$ : C $38.94 \%$; $\mathrm{H} 4.49 \%$; calcd for C14H20I2 0.1 hexane: C: $38.91 \%, \mathrm{H} 4.79 \%$; found C: $38.94, \mathrm{H} 4.49 \%$.

12,13,14,17-Tetramethyl-2,9-diphenyl-19-oxaheptacyclo-[10.3.2.12,9.110,13.01,10.03,8.014,17] nonadec-3,5,7-triene (5). A solution of tert-butyllithium (1.6m in pentane, $0.61 \mathrm{~mL}, 0.97 \mathrm{mmol}$ ) was slowly added, under stirring, to a cold ( $678 \mathrm{C})$ solution of $3(252 \mathrm{mg}, 0.6 \mathrm{mmol})$ and 1,3diphenylisobenzofuran $(186 \mathrm{mg}, 0.68 \mathrm{mmol})$ in anhydrous THF $(10 \mathrm{~mL})$. The reaction mixture was kept at this temperature for $30 \mathrm{~min}$ and then it was allowed to warm to room temperature. Methanol $(5 \mathrm{~mL})$ and water $(10 \mathrm{~mL})$ were added dropwise and the mixture was extracted with diethyl ether $(3 \square 50 \mathrm{~mL})$. The combined organic extracts were dried over $\mathrm{Na} 2 \mathrm{SO} 4$, filtered, and concentrated in vacuo to dryness to give a yellow oil. Purification by column chromatography (EtOAc/n-hexane mixtures) gave 5 ( $96 \mathrm{mg}$, $37 \%$ yield) as a pale yellow solid, m.p. 182-1838C. $1 \mathrm{H} \mathrm{NMR} \mathrm{(500} \mathrm{MHz,} \mathrm{CDCl3):} \mathrm{d=0.42} \mathrm{[d,} \mathrm{J=11.5}$ $\mathrm{Hz}, 2 \mathrm{H}, 11(16)-\mathrm{Ha}$ ], 0.80 (s, 6H) and 0.85 (s, 6H) [C12(17)-CH3 and C13(14)-CH3], 0.94 [dd, J=11.0 $\mathrm{Hz}, \mathrm{J}=2.5 \mathrm{~Hz}, 2 \mathrm{H}, 15(18)-\mathrm{Hb}], 1.06$ [d, J=11.0 Hz, 2H, 15(18)-Ha], 1.51 [dd, J=11.5 Hz, J'=2.5 Hz, 2H, 11(16)-Hb], 7.15 [m, 2H, 5(6)-H], 7.32 [m, 2H, 4(7)-H], 7.37 (tt, 2H, J=7.5 Hz, J'=1.5 Hz, Ar-Hpara), 7.49 (broad t, J=7.5 Hz, 4H, Ar-Hmeta), 7.78 ppm (d, J=8.0 Hz, J'=1.5 Hz, 4H, Ar-Hortho); 13C NMR (125.7 MHz, $\mathrm{CDCl} 3): \mathrm{d}=15.6(\mathrm{CH} 3)$ and 15.8 (CH3) [C12(17)-CH3 and C13(14)-CH3], 39.2 [CH2, C11(16)], 41.0 [CH2, C15(18)], 44.6 [C, C12(17)], 45.4 [C, C13(14)], 55.3 [C, C1(10)], 88.8 [C, C2(9)], 119.6 [CH, C4(7)], 125.0 (CH, Cortho-C6H5), 126.1 [CH, C5(6)], $127.0(\mathrm{CH}, \mathrm{Cpara}-\mathrm{C} 6 \mathrm{H} 5), 128.2(\mathrm{CH}$, Cmeta-C6H5), 138.3 (C, Cipso-C6H5), 146.7 ppm [C, C3(8)]; IR (KBr): n=3061, 3024, 2943, 2913, 2860, 1597, 1457, 1446, 1370, 1342, 1302, 1272, 1217, 1178, 1155, 1119, 1021, 1001, 975, 936, 839, 
745, 712, 698, $674 \mathrm{~cm}$ 1; GC/MS (70 eV): m/z (\%): 458 (MC+, 1), 353 (36), 270 (100), 241 (13), 193 (5), 165 (8), 105 (5), 77 (4); Accurate mass [ESI(+)]: m/z calcd for C34H35O: $459.2682[\mathrm{M}+\mathrm{H}]+$; found: 459.2680; Anal calcd for C34H34O: C 89.04\%; H 7.47\%; calcd for C34H34O-0.05CH2Cl2 : C: $88.35 \%, \mathrm{H} 7.43 \%$; found C: $88.10, \mathrm{H} 7.63 \%$.

3,4,8,9-Tetramethyltetracyclo[4.4.0.03,9.04,8]decane (6), 4,5,6,7,12,-13,16,17ctamethylnonacyclo[8.4.4.12,5.16,9.01,10.02,9.04,7.012,17.013,16]-eicosane (7), and 3,4,8,9tetramethyl-1-[3,4,8,9-tetramethyltetracyclo[4.4.0.03,9.04,8]dec-1-yl]-tetracyclo[4.4.0.03,9.04,8]decane (8). Finely cut sodium $(0.49 \mathrm{~g}, 21.5 \mathrm{mmol})$ was added to boiling anhydrous 1,4-dioxane $(25 \mathrm{~mL})$ and the mixture was heated with stirring under an argon atmosphere until the metal melted. Then, solid 3 (0.95 g, $2.15 \mathrm{mmol}$ ) was added and the mixture was heated under reflux for $4 \mathrm{~h}$. The reaction mixture was cooled to room temperature and filtered through Celite]. The solid residue was washed with diethyl ether and n-pentane, and the combined filtrate and washings were concentrated under reduced pressure to give a solid white residue ( $151 \mathrm{mg}$, aprox. $35 \%$ yield). GC/MS spectrometry showed the presence of three main components with the following retention times, $\mathrm{m} / \mathrm{z}$ of the molecular ions and relative areas (12.3 min, 190, 20.8\%; $24.2 \mathrm{~min}, 376,11.5 \%$; $25.1 \mathrm{~min}, 378,45.6 \%)$. By sublimation (100 8C/1 atm), pure tetracycle 6 was obtained (19 mg, 5\%yield), m.p. 189-1908C. 1H NMR (400 MHz, CDCl3): $\mathrm{d}=0.56$ [d, J=11.0 Hz, 4H, 2(5,7,10)-Ha], 0.93 (s, 12H, 3(4,8,9)-CH3], 1.70 [d, J=11.0 Hz, 4H, 2(5,7,10)-Hb], 2.24 ppm [s, 2H, 1(6)-H]; 13C NMR (100.6 MHz, CDCl3): d=15.8 (CH3), $32.9(\mathrm{CH})$, 38.1 (CH2), 45.3 ppm (C); IR (KBr): $\mathrm{n}=3447,2946,2864,1458,1381,1369,1323,1116,1096,1028$, $927 \mathrm{~cm} \mathrm{1;} \mathrm{GC/MS} \mathrm{(70} \mathrm{eV):m/z} \mathrm{( \% ):} 190$ (MC+, 43), 120 (100), 119 (30), 108 (31), 107 (34), 105 (51), 95 (16), 93 (39), 91 (34), 77 (19). By recrystallization of the remaining mixture from n-pentane, pure dimer 7 (36 mg, 9\%yield) was isolated by filtration, m.p. $>3008 \mathrm{C}$. 1H NMR (400 MHz, CDCl3): d=0.64 [d, J=13.5 Hz, 8H, 3(8,11,14,15,18,19,20)-Ha], 0.91 (s, 24H, 4(5,6,7,12,13,16,17)-CH3], 1.97 ppm [d, $\mathrm{J}=13.5 \mathrm{~Hz}, 8 \mathrm{H}, 3(8,11,14,15,18,19,20)-\mathrm{Hb}]$; 13C NMR (100.6 MHz, CDCl3): d=15.8 (CH3), 38.9 (CH2), 45.3 [C, 4(5,6,7,12,13,16,17)-C], 47.0 ppm [C, 1(2,9,10)-C]; IR (KBr): n= 2945, 2860, 1699, 1445, 1382, 1297, 1215, $1115 \mathrm{~cm} \quad$ 1; GC/MS (70 eV): m/z (\%): $376(\mathrm{MC}+, 12), 190$ (24), 189 (17), 188 (69), 187 (100), 186 (55), 185 (15), 173 (71), 171 (34), 145 (21), 131 (16), 119 (42), 105 (17), 91 (19), 79 (15); Anal calcd for C28H40 : C 89.29\%; H 10.71\%; found C: 89.07, H 10.71\%. The solid remaining after concentration of the mother liquors was washed with dichloromethane to give the pure dihydrodimer 8 (37 mg, 9\% yield), m.p. 199-2008C. 1H NMR (400 MHz, CDCl3): d=0.62 [d, J=11.6 $\mathrm{Hz}, 4 \mathrm{H}, 2\left(2^{\prime}, 10,10^{\prime}\right)-\mathrm{Ha}$ ], 0.69 [dd, J=11.2 Hz, J'=2.8 Hz, 4H, 5(5',7,7')-Ha], 0.91 (s, 12H) and 0.93 (s, 12H) [3(3',9,9')-CH3, and 4(4',8,8')-CH3], 1.62 [d, J=11.2 Hz, 4H, 2(2',10,10')-Hb], 1.71 [dd, J=11.2 $\left.\mathrm{Hz}, \mathrm{J}^{\prime}=1.4 \mathrm{~Hz}, 4 \mathrm{H}, 5\left(5^{\prime}, 7,7^{\prime}\right)-\mathrm{Hb}\right], 2.31 \mathrm{ppm}\left[\mathrm{m}, 2 \mathrm{H}, 6\left(6^{\prime}\right)-\mathrm{H}\right]$; 13C NMR (100.6 MHz, CDCl3): $\mathrm{d}=$

15.8 (CH3), 16.1 (CH3), 36.9 [CH, 6(6')-C], 39.2 [CH2, 2(2',10,10')-C], 39.4 [CH2, 5(5', 7,7')-C], 44.8 (C), and 45.3 (C) [3(3',9,9')-C and 4(4',8,8')-C], 47.5 ppm [C, 1(1')-C]; IR (KBr): n=2943, 2861, 1457, 1381, 1371, 1324, 1258, 1224, 1095, 1061, 1033, $799 \mathrm{~cm} \quad$ 1; GC/MS (70 eV): m/z (\%): 378 (MC+, 21), 296 (49), 214 (18), 189 (65), 188 (68), 187 (20), 173 (33), 133 (21), 120 (25), 119 (100), 107 (50), 105 (29), 95 (54), 93 (16), 91 (34), 80 (19), 67 (20); Anal calcd for C28H42: C 88.82\%; H 11.18\%; calcd for $\mathrm{C} 28 \mathrm{H} 42 \cdot 0.1 \mathrm{CH} 2 \mathrm{Cl} 2$ : C $87.18 \%$; H 10.99\%; found C: $87.43, \mathrm{H} 11.11 \%$. 
[1] a)W. T. Borden, Chem. Rev. 1989, 89, 1095 - 1109; b) H. Hopf, Classics in Hydrocarbon Chemistry: Syntheses, Concepts, Perspectives, Wiley-VCH, Weinheim, 2000, pp. 122 - 137; c)

Hydrocarbons (Ed: H. Dodziuk), Wiley-VCH,Weinheim, 2009, pp. 112 - 121; e) S. P. Gavrish, J. Comput. Chem. 2012, 33, $2173-2179$.

[2] For recent examples: a) P. Camps, M. R. MuÇoz, S. V] zquez, Tetrahedron 2006, 62, 7645 7652; b) P. Camps, G. Colet, S. Delgado, M. R. MuÇoz, M. A. Peric】 s, L. Sol】 , S. V】 zquez, Tetrahedron 2007, 63, $4669-4679$.

Alachraf, I. M. Oppel, G. Dyker, J. Org. Chem. 2009, 74, 8355 - 8358; d) S. Ioannou, H.

Krassos, A. V. Nicolaides, Tetrahedron 2013, 69, 8064 - 8068.

4] Gaussian09 (RevisionA.1): M. J. Frisch et al., see the Supporting Information for details about the calculations.

For a definition of the pyramidalization angle, see: W. V. Volland, E. R. Davidson, W. T. Borden, J. Am. Chem. Soc. 1979, 101, 533 - 537. For fullerenes and related compounds, pyramidalizations are typically reported as POAV angles. The POAV angle of 4 is 17.98 . For a definition of the POAV angle, see: a) R. C. Haddon, J. Phys. Chem. 1987, 91, 3719 - 3720; b) R. C. Haddon, J. Am. Chem. Soc. 1990, 112, 3385 - 3389; c) R. C. Haddon, J. Phys. Chem. A $2001,105,4164-4165$.

a) P. Camps, M. Font-Bardia, N. M[ ndez, F. P[ rez, X. Pujol, X. Solans, S. V] zquez, M. Vilalta, Tetrahedron 1998, 54, 4679 - 4696; b) S. VD zquez, J. Chem. Soc. Perkin Trans. 2 $2002,2100-2103$.

[8] K. Kulbitski, G. Nisnevich, M. Gandelman, Adv. Synth. Catal. 2011, 353, $1438-1442$. 
[9] a) Crystal structure analysis of 7: a translucent colorless prismlike specimen of 7, approximate dimensions $0.071 \mathrm{~mm} \rrbracket 0.093 \mathrm{~mm} \rrbracket 0.109 \mathrm{~mm}$, was used for the X-ray crystallographic analysis. The X-ray intensity data were measured on a D8 Venture system equipped with a Multilayer monochromator and a Mo microfocus $(1=0.71073 \quad)$. A total of 1473 frames were SAINT software package using a narrow-frame algorithm. The integration of the data using a monoclinic unit cell yielded a total of 34804 reflections to a maximum q angle of $28.578(0.74$ resolution), of which 2683 were independent (average redundancy 12.972, completeness= $100.0 \%$, Rint $=5.79 \%)$ and $2224(82.89 \%)$ were greater than $2 \mathrm{~s}(\mathrm{~F} 2)$. The final cell constants of $\mathrm{a}=6.978(6), \mathrm{b}=11.110(10), \mathrm{c}=14.848(13) \quad, \mathrm{b}=113.90(4) 8$, volume $=1052.4(16) \quad 3$, are based upon the refinement of the XYZ-centroids of 87 reflections above $20 \mathrm{~s}(\mathrm{I})$ with 7.3488 $<2 \mathrm{q}<54.878$. Data were corrected for absorption effects using the multi-scan method (SADABS). The ratio of minimum to maximum apparent transmission was 0.955 . The structure was solved and refined using the Bruker SHELXTL Software Package, with $Z=2$ for the formula unit, $\mathrm{C} 28 \mathrm{H} 40$. The final anisotropic full-matrix leastsquares refinement on F2 with 155 variables converged at $\mathrm{R} 1=5.13 \%$, for the observed data and $\mathrm{wR} 2=14.36 \%$ for all data. The goodness-offit was 1.065 . The largest peak in the final difference electron density synthesis was 0.571 e $\quad 3$ and the largest hole was $\quad 0.444$ e $\quad 3$ with an RMS deviation of 0.068 e $\quad 3$. On the basis of the final model, the calculated density was $1.188 \mathrm{gcm} \quad 3$ and $\mathrm{F}(000), 416 \mathrm{e} .8 \mathrm{H}$ atoms were located from a difference synthesis and refined with an isotropic temperature factor equal to 1.2 time the equivalent temperature factor of the atom which are linked and $12 \mathrm{H}$ atoms were computed and refined, using a riding model, with an isotropic temperature factor equal to 1.2 time the equivalent temperature factor of the atom which are linked; b) crystal structure analysis of 8: a colorless Prism-like specimen of 8, approximate dimensions $0.090 \mathrm{~mm} \square 0.209$ $\mathrm{mm} \rrbracket 0.623 \mathrm{~mm}$, was used for the X-ray crystallographic analysis. The X-ray intensity data were measured on a D8 Venture system equipped with a multilayer monochromator and aMo microfocus $(1=0.71073)$.Atotal of 1064 frames were collected. The total exposure time was 17.73 h. The frames were integrated with the Bruker SAINT software package using a narrow- 
frame algorithm. The integration of the data using a monoclinic unit cell yielded a total of 40995 reflections to a maximum q angle of 28.338 ( 0.75 resolution), of which 5377 were independent (average redundancy 7.587 , completeness $=98.8 \%$, Rint $=5.79 \%$, Rsig $=3.37 \%$ ) and $5037(93.23 \%)$ were greater than $2 \mathrm{~s}(\mathrm{~F} 2)$. The final cell constants of $\mathrm{a}=22.792(3), \mathrm{b}=7.8099(8)$, $\mathrm{c}=12.4331(15) \quad, \mathrm{b}=100.517(4) 8$, volume $=2176.0 .(4) \quad 3$, are based upon the refinement of the XYZ-centroids of 143 reflections above $20 \mathrm{~s}(\mathrm{I})$ with $7.1428<2 \mathrm{q}<52.438$. Data were corrected for absorption effects using the multi-scan method (SADABS). The ratio of minimum to maximum apparent transmission was 0.775 . The structure was solved and refined using the Bruker SHELXTL Software Package, with $Z=4$ for the formula unit, C28H42.The final anisotropic full-matrix least-squares refinement on F2 with 322 variables converged at $\mathrm{R} 1=8.25 \%$, for the observed data and $\mathrm{wR} 2=21.75 \%$ for all data. The goodness-of-fit was 1.071 . The largest peak in the final difference electron density synthesis was $0.426 \mathrm{e} \quad 3$ and the largest hole was 0.428 e $\quad 3$ with an RMS deviation of 0.099 e $\quad 3$. On the basis of the final model, the calculated density was $1.156 \mathrm{gcm} \quad 3$ and $\mathrm{F}(000), 840 \mathrm{e} .22 \mathrm{H}$ atoms were located from a difference synthesis and refined with an isotropic temperature factor equal to 1.2 time the equivalent temperature factor of the atom which are linked and $20 \mathrm{H}$ atoms were computed and refined, using a riding model, with an isotropic temperature factor equal to 1.2 time the equivalent temperature factor of the atom which are linked; c) the structures of 1, 3 and 5 were also established by X-Ray diffraction analysis. See supporting information for details. CCDC 994900, 994901, 994902, 994903 and 994904 contain the supplementary crystallographic data for this paper. These data can be obtained free of charge from The Cambridge Crystallographic Data Centre via www.ccdc.cam.ac.uk/data request/cif.

[10] M. Balasubramanian, Chem. Rev. 1962, 62, $591-598$.

[11] a) R. R. Sauers, J. Chem. Educ. 2000, 77, 332 - 332; b) K. Kakhiani, U. Lourderaj, W. Hu, D. Birney, W. L. Hase, J. Phys. Chem. A 2009, 113, 4570 - 4580.

[12] a) U. Biethan, U. v. Gizycki, H. Musso, Tetrahedron Lett. 1965, 6, 1477 - 1482; b) H. Musso,U. Biethan, Chem. Ber. 1967, 100, 119 -131; c) H. Musso, H. Klusacek, Chem. Ber. 1970, 103, 

3076 - 3086; d) B. Ahlquist, A. Almenningen, B. Benterud, M. Traetteberg, P. Bakken, W. L】 ttke, Chem. Ber. 1992, 125, 1217 - 1225.

319

320

321

[13] A. Otterbach, H. Musso, Angew. Chem. 1987, 99, 588 - 590; Angew. Chem. Int. Ed. Engl. $1987,26,554-555$.

[14] a) H.-M. Hutmacher, H.-G. Fritz, H. Musso, Angew. Chem. 1975, 87, 174 - 175; Angew. Chem. Int. Ed. Engl. 1975, 14, 180 - 181; b) H.-G. Fritz, H.-M. Hutmacher, H. Musso, G. Ahlgren, B. kermark, R. Karlsson, Chem. Ber. 1976, 109, 3781 - 3792; c) G. Kaiser, H. Musso, Chem. Ber. 1985, 118, $2266-2281$.

[15] Several double tetraasteranes are also known: a) V. T. Hoffmann, H. Musso, Angew. Chem. 1987, 99, 1036 - 1037; Angew. Chem. Int. Ed. Engl. 1987, 26, 1006 - 1007; b) V. T. Hoffmann, H. Musso, Chem. Ber. 1991, 124, $103-109$.

[16] a) C. A. Cupas, L. Hodakowski, J. Am. Chem. Soc. 1974, 96, 4668 - 4669; b) D. P. G. Hamon, G. F. Taylor, Tetrahedron Lett. 1974, 15, 155 - 158; c) D. P. G. Hamon, G. F. Taylor, Aust. J. Chem. 1976, 29, $1721-1734$.

[17] O. Hassel, B. Ottar, Acta Chem. Scand. 1947, 1, 929 - 943.

[18] a) R. Chauvin, J. Phys. Chem. 1992, 96, 9194 - 9197; b) R. S. Rowland, R. Taylor, J. Phys. Chem. 1996, 100, $7384-7391$.

[19] a) R. Gilardi, M. Maggini, P. E. Eaton, J. Am. Chem. Soc. 1988, 110, 7232 - 7234; b) M. Tanaka, A. Sekiguchi, Angew. Chem. 2005, 117, 5971 - 5973; Angew. Chem. Int. Ed. 2005, 44, $5821-5823$.

[20] R. A. Alden, J. Kraut, T. G. Traylor, J. Am. Chem. Soc. 1968, 90, $74-82$. 
344 Scheme 1. Synthesis, trapping, and dimerization of alkene 4. a) aq. $\mathrm{NaOH}$, reflux, then conc $\mathrm{HCl}, 70 \%$ 345 yield; b) 1,3-diiodo-5,5-dimethylhydantoin, 1,2-dichloroethane, 27\% yield; c) Na, 1,4-dioxane, reflux, 4 346 h; d) tBuLi, 1,3-diphenylisobenzofuran, THF, 678C, 37\% yield.

347

348 Figure 1. Crystal structure (ORTEP) of 7. Thermal ellipsoids shown at 50\% probability. Selected 349 distances [ ] ] and angles [8]: C2-C8 1.5844(19), C7-C8 1.5841(19), C4-C5 1.589(2), C4-C5a 350 1.542(2), C8-C9 1.5376(19), C4-C9 1.543(2); C3-C2-C10 109.44(11), C3-C2-C8 105.41(11), C10-C2351 C8 90.01(10), C2-C3-C4 99.61(11), H3a-C3-H3b 110.1 (15), C5a-C4-C5 90.05(11), C3-C4-C5 352 109.78(12), C4a-C5-C12 122.30(13), C12-C5-C13 101.86(12), C4a-C5-C4 89.95(11).

353

354 Figure 2. Known polycyclic compounds featuring boat cyclohexane rings.

355

356

Scheme 2. Hypothetical [2+2] cycloreversion of 7 into the dienes 13,14 , and 15 . 
SCHEME 1.

360

361

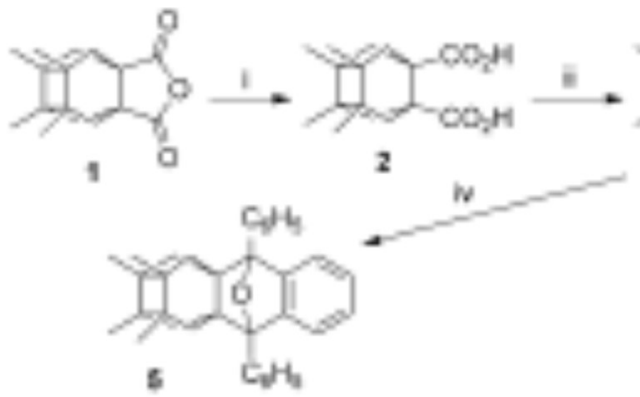

362

363

364 


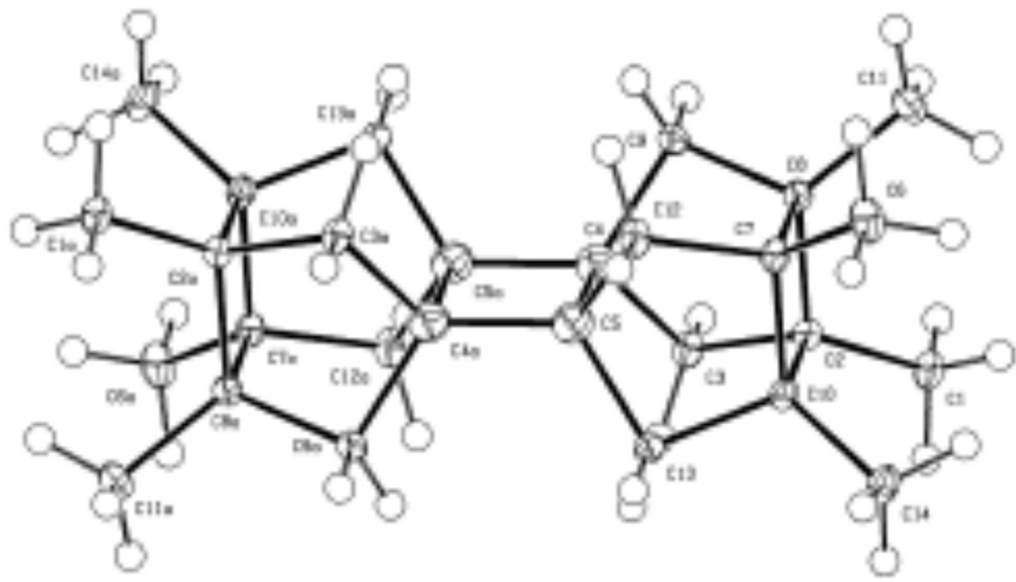

370 
371

372

373

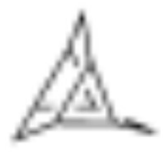

9

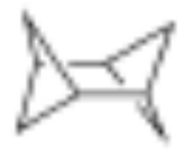

10
FIGURE 2

374

375

376

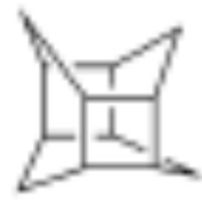

11

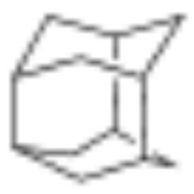

12 
SCHEME 2

378

379

380

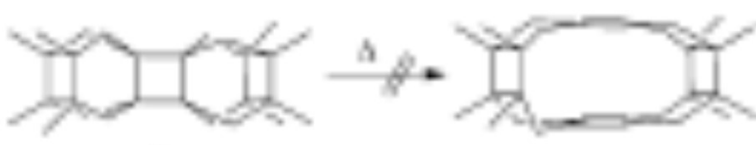

T

13

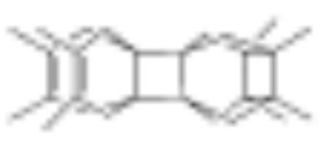

14

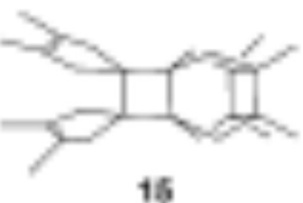

15

381 
382 Table 1. $\mathrm{H}-\mathrm{H}$ and $\mathrm{C}-\mathrm{C}$ distances between the flagpole hydrogen atoms and the flagpole carbon atoms in 383 boat cyclohexane and hydrocarbons 6-7 and 9-12.

\begin{tabular}{|c|c|c|c|c|}
\hline \multirow[t]{3}{*}{ Compound } & \multicolumn{2}{|c|}{$\mathrm{H}$-H distance [A]] } & \multicolumn{2}{|c|}{$\mathrm{C}-\mathrm{C}$ distance $[\dot{\mathrm{A}}]$} \\
\hline & $B 3 L Y P \mid$ & $M P 2 j$ & $B 3 L Y P /$ & $M P 2 /$ \\
\hline & $6.31 \mathrm{C}(\mathrm{d})$ & $6.31 \mathrm{C}(\mathrm{d})$ & $6.31 \mathrm{C}(\mathrm{d})$ & $6.31 \mathrm{C}$ (d) \\
\hline Cyclohesane & 2.349 & 2.289 & 2.739 & 2.710 \\
\hline 6 & 2.035 & 2.027 & 2.655 & 2.639 \\
\hline til & 2.054 & 2.042 & 2.684 & 2.668 \\
\hline $9 *$ & 3.252 & 3.238 & 2.990 & 2.979 \\
\hline 10 & 1.861 & 1.856 & 2.625 & 2.610 \\
\hline 11 & 2.505 & 2.488 & 2.814 & 2.800 \\
\hline 12 & 2.126 & 2.120 & 2.668 & 2.652 \\
\hline
\end{tabular}

